\title{
EULAR recommendations for patient education for people with inflammatory arthritis
}

\author{
Heidi A Zangi, ${ }^{1}$ Mwidimi Ndosi, ${ }^{2}$ Jo Adams, $^{3}$ Lena Andersen, ${ }^{4}$ Christina Bode, ${ }^{5}$ \\ Carina Boström, ${ }^{6}$ Yvonne van Eijk-Hustings, ${ }^{7,8}$ Laure Gossec, ${ }^{9,}{ }^{10}$ Jana Korandová, ${ }^{11}$ \\ Gabriel Mendes, ${ }^{12}$ Karin Niedermann, ${ }^{13}$ Jette Primdahl, ${ }^{14,15,16}{ }^{\text {Michaela Stoffer, }}{ }^{17}$ \\ Marieke Voshaar, ${ }^{18}$ Astrid van Tubergen ${ }^{19}$
}

\begin{abstract}
Handling editor Hans WJ Bijlsma

- Additional material is published online only. To view please visit the journal online (http://dx.doi.org/10.1136/ annrheumdis-2014-206807).
\end{abstract}

For numbered affiliations see end of article.

\section{Correspondence to $\mathrm{Dr}$} Heidi A Zangi, National Advisory Unit on Rehabilitation in Rheumatology, Department of rheumatology,

Diakonhjemmet Hospital, PO Box 23 Vinderen, Oslo 0319, Norway; heidi.zangi@ diakonsyk.no

Received 16 October 2014 Revised 19 January 2015 Accepted 10 February 2015 Published Online First 3 March 2015
CrossMark

To cite: Zangi $\mathrm{HA}$,

Ndosi M, Adams J, et al.

Ann Rheum Dis

2015;74:954-962.

\section{ABSTRACT}

Objectives The task force aimed to: (1) develop evidence-based recommendations for patient education (PE) for people with inflammatory arthritis, (2) identify the need for further research on PE and (3) determine health professionals' educational needs in order to provide evidence-based PE.

Methods A multidisciplinary task force, representing 10 European countries, formulated a definition for PE and 10 research questions that guided a systematic literature review (SLR). The results from the SLR were discussed and used as a basis for developing the recommendations, a research agenda and an educational agenda. The recommendations were categorised according to level and strength of evidence graded from A (highest) to $D$ (lowest). Task force members rated their agreement with each recommendation from 0 (total disagreement) to 10 (total agreement).

Results Based on the SLR and expert opinions, eight recommendations were developed, four with strength A evidence. The recommendations addressed when and by whom PE should be offered, modes and methods of delivery, theoretical framework, outcomes and evaluation. A high level of agreement was achieved for all recommendations (mean range 9.4-9.8). The task force proposed a research agenda and an educational agenda.

Conclusions The eight evidence-based and expert opinion-based recommendations for PE for people with inflammatory arthritis are intended to provide a core framework for the delivery of PE and training for health professionals in delivering PE across Europe.

\section{INTRODUCTION}

Patient education (PE) is recommended as an integral part in established recommendations for the management of early arthritis and ankylosing spondylitis (AS). ${ }^{1}{ }^{2}$ PE comprises all educational activities provided for patients, including aspects of therapeutic education, health education and health promotion. ${ }^{3}$ Previous systematic reviews on various PE interventions in patients with rheumatoid arthritis (RA) documented significant short-term improvements in knowledge, coping behaviour, pain, disability and depression, but long-term effects were inconsistent. $^{4-7}$

During the last decades there has been an ongoing development within healthcare, moving away from the view of health professionals (HPs) as the only experts and providers of knowledge and patients as passive recipients towards a more collaborative approach. Patients have been recognised as active agents in managing their illness and own healthcare. ${ }^{8}$ The principle of 'shared decision making' allowing patients and their providers to make healthcare decisions together, based on the best scientific evidence available, as well as the patient's values and preferences, is increasingly accepted. ${ }^{9}$ The primary goal of PE is no longer only knowledge transfer and disease control, but also to enable patients to manage their illness, adjust to their condition and maintain quality of life. ${ }^{10} 11$

Moreover, PE has been influenced by scientific developments and changes in society. Biomedical advancements, new pharmacological treatment options, and better knowledge about the risk for developing comorbidities require new approaches to communicate with patients in a timely and meaningful way. ${ }^{12}{ }^{13}$ In several countries, larger healthcare teams with more specialised HPs have been established to meet the complexity of the healthcare needs of patients with rheumatic diseases. ${ }^{14}{ }^{15}$ Furthermore, the development of e-health and the use of mobile telehealth platforms have introduced new possibilities for communication and delivery of information, which are increasingly applied in PE. Finally, the increase in immigration and cultural diversity in many European countries is challenging for planning and facilitating effective PE for all patients. ${ }^{8}$

Informal discussions among multidisciplinary HPs at the European League Against Rheumatism (EULAR) annual congress in 2012 and succeeding email correspondences revealed that great variety exists in the content and modes of delivery of PE across European countries. In some countries PE is still limited to providing knowledge in order to improve patients' adherence to treatment. Additionally, there seems to be a large variation in HPs' involvement in PE. ${ }^{15}$ To what extent different HPs participate in PE is likely to depend on their competency, availability and education, as well as the organisation of the healthcare system. ${ }^{16}$ Based on these initial discussions, an EULAR task force was convened with the following objectives: (1) to develop a set of recommendations for PE for people with inflammatory arthritis (IA) (2) to identify the need for further research and (3) to define 
HPs' educational needs for providing evidence-based PE. The recommendations would allow standardisation and improvement of PE for people with IA across Europe. The target groups for the recommendations are rheumatology HPs including rheumatologists, patients with IA, policy makers and patient and professional organisations.

\section{METHODS}

The EULAR standardised operation procedures for the elaboration, evaluation, dissemination and implementation of recommendations ${ }^{17}$ were followed.

\section{The task force}

The multidisciplinary task force comprised 15 experts including three patients, five nurses, two occupational therapists (OTs), two physiotherapists (PTs), a psychologist and two rheumatologists/epidemiologists with clinical experience and/or academic knowledge in the field of PE. They represented ten European countries (Austria, Czech Republic, Denmark, France, the Netherlands, Norway, Portugal, Sweden, Switzerland and UK). People who had taken part in the initial discussions, but were not included in the task force, were invited to participate in a 'consultation group'. This group comprised $20 \mathrm{HPs}$, such as OTs, PTs, nurses and rheumatologists, but no patients were included.

Before the first task force meeting in 2013 one of the members was tasked with reviewing the literature of existing PE definitions. An overview was presented and thoroughly discussed during the meeting. Common elements in the definitions were identified and the following definition was formulated, based on consensus among the task force members: "PE is a planned interactive learning process designed to support and enable people to manage their life with IA and optimise their health and well-being." This interactive learning process includes a wide range of educational activities, such as provision of knowledge, written material, e-health, self-management programmes (SMPs), cognitive behavioural therapy (CBT), mindfulness, stress management, individual consultations with HPs, sharing experiences among patients, motivational discussions, exercise counselling, lifestyle change interventions and self-help courses. Moreover, the task force agreed that the recommendations should be based on the principle of shared decision making. ${ }^{9}$ Following this consensus process, the task force formulated 10 research questions to guide the systematic literature review (SLR) (see online supplementary file 1).

\section{Systematic literature review}

An extensive systematic literature search in Medline, Embase, PsycINFO, Cochrane Library and CINAHL from January 2003 up to September 2013 of publications in English, German, French or Spanish describing any kind of PE activities, was conducted (details provided in online supplementary file 2). No limitations regarding study type or research design was applied. The inclusion criteria were IA, confined to RA, AS and psoriatic arthritis (PsA) and adults (age $\geq 18$ years). All abstracts were independently read by two reviewers, and by a third reviewer in case of disagreement. The papers of the included abstracts were reviewed in full-text. Papers were excluded if they did not include any formal PE intervention (as defined above) or did not address the patient perspective on PE. The task force members were asked to review the final list of included papers and could add studies that were not captured by the SLR.

\section{Developing the recommendations}

The results of the SLR were presented and discussed during the second task force meeting in 2014 and eight recommendations were developed. The strength of each recommendation was based on the categories of evidence defined by the EULAR standardised operation procedures, graded from A (highest) to D (lowest) ${ }^{17}$ (see online supplementary file 3 ). The recommendations were emailed to each task force member for final independent voting and approval. The level of agreement was recorded on a $0-10$ point scale $(0=$ no agreement at all; $10=$ full agreement, table 1). In addition to the task force, the consultation group was invited to independently rate their level of agreement with each recommendation to obtain an indication of the agreement among people who are supposed to use the recommendations in clinical practice.

\section{RESULTS}

Figure 1 shows the flow chart of the SLR. In total, 115 publications were included, comprising 11 systematic reviews/ meta-analyses, 36 randomised controlled trials (RCTs) (reported in 44 papers), 7 controlled clinical trials (CCTs), 9 pre-post-test studies, 23 cross-sectional surveys and 21 qualitative studies. The majority of patients in the included studies was female (58-100\%), diagnosed with RA (82\%) and had relatively long disease duration (mean 6-16 years). Ten studies included patients with AS and/or PsA and five studies included only patients with early disease duration ( $<2$ years).

\section{Recommendations}

Two overarching principles and eight evidence-based and expert-opinion based recommendations were developed, four of which achieved strength A. A high level of agreement was achieved for all recommendations; mean range 9.4-9.8 in the task force and 8.2-9.2 in the consultation group (table 1).

\section{Recommendation 1: PE as an integral part of standard care}

The task force agreed that PE should be an integral part of standard care for people with IA. Category I evidence showed that various individual and group educational interventions had beneficial short-term effects in patients with RA. ${ }^{3}{ }^{7}$ Three $\mathrm{RCTs}^{18-20}$ and one $\mathrm{CCT}^{21}$ showed that individual or group PE enhanced adherence with pharmacological treatment and knowledge of medication side effects. Moreover, one meta-analysis and four RCTs concluded that group educational programmes significantly improved disease knowledge, coping skills and physical and psychological health status. ${ }^{22-25}$ Several RCTs ${ }^{26-31}$ and $\mathrm{CCTs}^{32} 33$ demonstrated that PE supplementary to physical therapy or joint protection exercises had positive influence on physical function and activity, and reduced pain. Furthermore, consistent evidence showed that CBT and stress management programmes improved psychological health after intervention and at follow-up (4-18 months). ${ }^{34-42}$

Finally, there was consensus in the task force that PE would increase patients' involvement in their disease management, but this was only supported by one cross-sectional study, ${ }^{43}$ in which high levels of perceived knowledge of the disease were positively associated with involvement in healthcare.

\section{Recommendation 2: PE throughout the course of the disease}

The task force emphasised the importance of offering timely PE. Individual patients' educational needs may vary, related to their disease stage and to fluctuations in their physical and 
Table 1 Recommendations for patient education for people with inflammatory arthritis

\section{Overarching principles}

1. Patient education is a planned interactive learning process designed to support and enable people to manage their life with inflammatory arthritis and optimise their health and well-being

2. Communication and shared decision making between people with inflammatory arthritis and their healthcare professionals are essential for effective patient education

\begin{tabular}{|c|c|c|c|c|}
\hline \multirow[b]{2}{*}{ Recommendations } & \multirow[b]{2}{*}{$\begin{array}{l}\text { Category of } \\
\text { evidence }\end{array}$} & \multirow[b]{2}{*}{$\begin{array}{l}\text { Strength of } \\
\text { recommendation }\end{array}$} & \multicolumn{2}{|c|}{$\begin{array}{l}\text { Level of agreement } \\
\text { mean (SD) }\end{array}$} \\
\hline & & & $\begin{array}{l}\text { Task } \\
\text { force }\end{array}$ & $\begin{array}{l}\text { Consultation } \\
\text { group }\end{array}$ \\
\hline $\begin{array}{l}\text { 1. Patient education should be provided for people with inflammatory arthritis as an integral part of } \\
\text { standard care in order to increase patient involvement in disease management and health promotion }\end{array}$ & $1 A-2 B$ & $A-C$ & $9.6(0.8)$ & $9.2(1.8)$ \\
\hline $\begin{array}{l}\text { 2. All people with inflammatory arthritis should have access to and be offered patient education } \\
\text { throughout the course of their disease including as a minimum; at diagnosis, at pharmacological } \\
\text { treatment change and when required by the patient's physical or psychological condition }\end{array}$ & $3-4$ & $C-D$ & $9.6(0.7)$ & $9.1(1.8)$ \\
\hline $\begin{array}{l}\text { 3. The content and delivery of patient education should be individually tailored and needs-based for } \\
\text { people with inflammatory arthritis }\end{array}$ & 1B & A & $9.8(0.6)$ & $9.1(2.3)$ \\
\hline $\begin{array}{l}\text { 4. Patient education in inflammatory arthritis should include individual and/or group sessions, which can } \\
\text { be provided through face-to-face or online interactions, and supplemented by phone calls, written or } \\
\text { multimedia material }\end{array}$ & $1 A-B$ & A & $9.5(0.7)$ & $8.9(2.4)$ \\
\hline $\begin{array}{l}\text { 5. Patient education programmes in inflammatory arthritis should have a theoretical framework and be } \\
\text { evidence-based, such as self-management, cognitive behavioural therapy or stress management }\end{array}$ & $1 A-B$ & A & $9.5(0.9)$ & $8.8(2.2)$ \\
\hline $\begin{array}{l}\text { 6. The effectiveness of patient education in inflammatory arthritis should be evaluated and outcomes used } \\
\text { must reflect the objectives of the patient education programme }\end{array}$ & 4 & $D$ & $9.6(0.8)$ & $8.3(1.8)$ \\
\hline $\begin{array}{l}\text { 7. Patient education in inflammatory arthritis should be delivered by competent health professionals and/or } \\
\text { by trained patients, if appropriate, in a multidisciplinary team }\end{array}$ & 3 & $C$ & $9.5(0.8)$ & $8.4(2.0)$ \\
\hline $\begin{array}{l}\text { 8. Providers of patient education in inflammatory arthritis should have access to and undertake specific } \\
\text { training in order to obtain and maintain knowledge and skills }\end{array}$ & $3-4$ & $C-D$ & $9.4(0.8)$ & $8.2(1.6)$ \\
\hline
\end{tabular}

psychological health condition. Educational needs may be identified by the patients themselves as well as by HPs and should be regularly monitored. Educational and support needs may be most salient at times when patients are more likely to be experiencing change or pressure, such as in the early stages of their disease, when new pharmacological treatment is initiated and when their everyday life is affected. ${ }^{44}{ }^{45}$ Differing educational needs may also appear when patients experience flares, worsening or comorbidities, and when the disease interferes with daily activities, life events and family roles. ${ }^{46-48}$

\section{Recommendation 3: tailored and needs-based PE}

The task force stated that PE should be tailored to the individual patient's needs. Several RCTs supported that individual counselling with a competent HP, either in one-by-one consultations or in combination with group sessions had beneficial health effects. $^{19} 29 \quad 37 \quad 49-51$ Cross-sectional and qualitative studies exploring patients' needs and expectations described a wide range of educational needs, such as knowledge and management of the disease, knowledge of side effects and risk factors, nonpharmacological treatment, pain control and self-help methods, as well as activity regulation, physical exercises and behaviour change. $^{44} 47$ 52-60 In general, patients' levels of knowledge about the disease were low to moderate and patients expressed they had received insufficient information. ${ }^{476162}$ Patients with IA wanted to be recognised as more than their disease, to be enabled to use their own resources and to re-engage in previously abandoned activities. ${ }^{55} 57$ 63-65 Moreover, PE should include discussion on emotional issues and support from HPs in coping with emotional distress. ${ }^{64-66}$

\section{Recommendation 4: modes of delivery of PE}

The SLR showed that PE is provided in various modes; individual face-to-face-meetings, ${ }^{19} \begin{array}{llllllll}20 & 23 & 26 & 30 & 37 & 42 & 67-73\end{array}$ groups, ${ }^{24} 25 \quad 28 \quad 34-36 \quad 38-41 \quad 74-79$ a combination of the two $^{27} 29495080$ and online. ${ }^{81-83}$ Category I evidence was found for individual counselling. Interactive individual education by rheumatologists improved adherence to medication regimen. ${ }^{19}{ }^{20}$ Individual counselling by OTs and PTs led to increased use of self-management strategies, such as hand exercises, joint protection and activity regulation. ${ }^{26} 7172$ Individual counselling by psychologists reduced depression, anxiety and total use of healthcare. ${ }^{37} 4269$ Individual counselling supplementary to physical exercise improved health status, adherence with exercise programmes and physical activity recommendations. ${ }^{29} 50518084$ Individual counselling by nurses, supplementary to group education improved disease knowledge, well-being, pain and self-management behaviours. ${ }^{27} 49$

Various group interventions focusing on active coping with emotional distress and daily life stressors improved functional and emotional health status, patients' coping strategies ${ }^{28} 31 \quad 34-36$ 38-41 $74 \quad 76$ and perceived social support. ${ }^{85}$ Finally, two $\mathrm{RCTs}^{80} 82$ and one pre-post-test study ${ }^{83}$ demonstrated that interactive online programmes contributed to improvement in health status, pain, physical limitations and levels of physical activity.

\section{Recommendation 5: theoretical framework and evidence for PE}

The task force agreed that PE should be based on a theoretical framework and be evidence-based. Four categories of PE interventions were described in the included studies: educational programmes (32 studies), ${ }^{18-21} 23-334950707173$ 76-78 8083 86-91 SMP (7 studies), ${ }^{74} 75 \quad 8292-95$ CBT (9 studies) ${ }^{34-3942} 6896$ and stress management programmes (6 studies). ${ }^{34} 4041699798$ The educational programmes mainly aimed to enhance knowledge, adherence to treatment, performance of physical function, joint protection and healthy lifestyle. The methods used were primarily didactic, instructions, counselling and practical exercises. These programmes were typically based on clinical experience and knowledge and were not underpinned by a theoretical framework. In contrast, the SMP and CBT interventions were based on 
Figure 1 Flow chart of the systematic literature review (SLR). CCT, controlled clinical trial; IA, inflammatory arthritis; $\mathrm{RCT}$, randomised controlled trial.

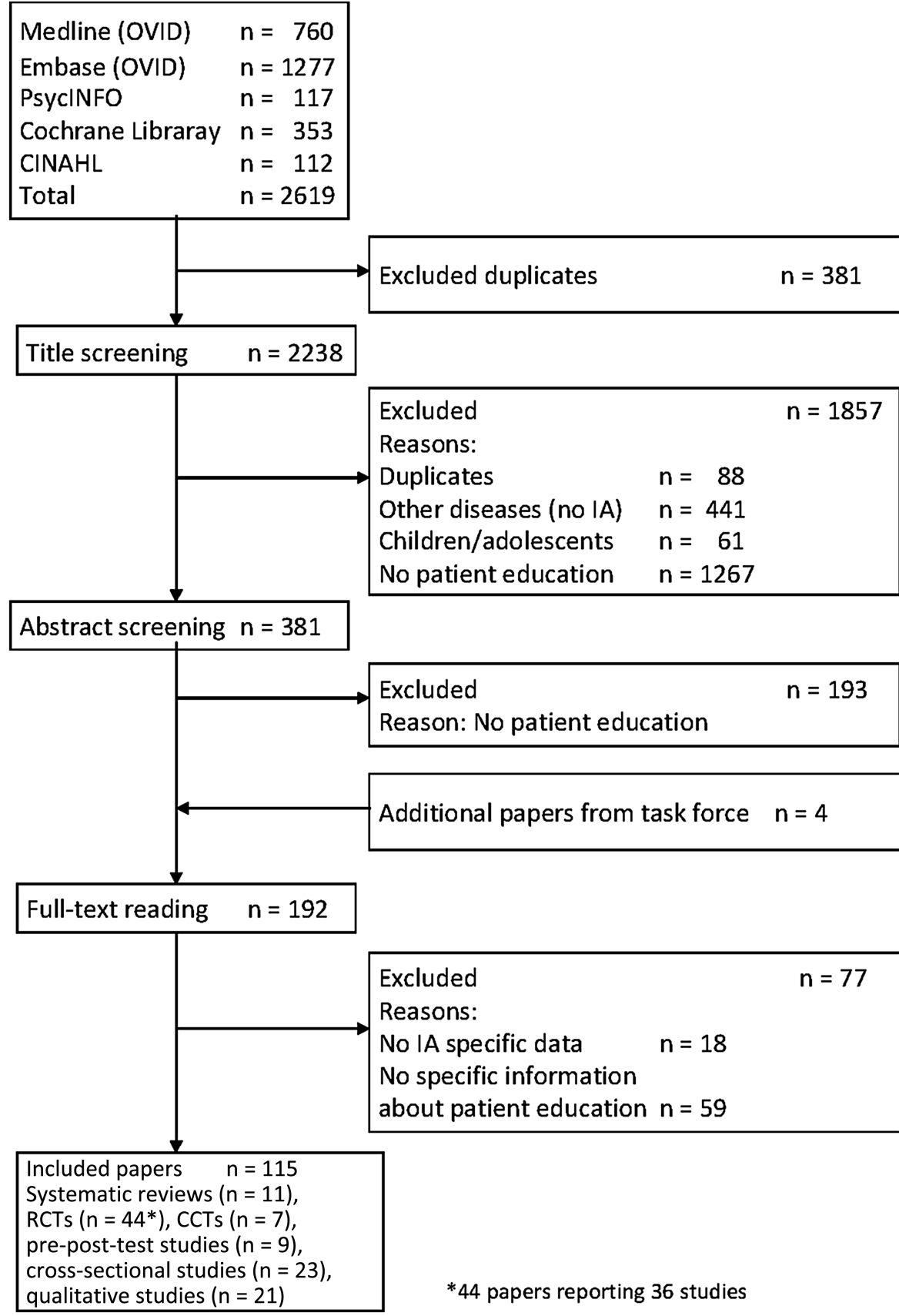

frameworks derived from social cognitive theory ${ }^{99}$ and cognitive behavioural theories. ${ }^{100}$ In addition to provision of knowledge, these programmes were targeted at improving coping and psychological health status, facilitating behaviour change and adoption of health promoting behaviours. Participants were actively involved in goal-setting, problem-solving, group discussions and in preparing action plans. Furthermore, CBT interventions focussed on cognitive restructuring of beliefs. ${ }^{100} 101$ The stress management programmes were mainly adapted from ancient Buddhist practices including yoga and breathing exercises, training of mindfulness meditation and acceptance. ${ }^{102}$ The main aims of these programmes were to enhance well-being by improving stress management skills, alleviate emotional distress, ${ }^{34} 404169$ and promote a constructive relationship with positive and negative emotions. $^{102}$

Recent systematic reviews have concluded that various group programmes (SMP, CBT and stress management) demonstrated small, but positive impact on self-reported physical activity levels, pain, disability, depressive symptoms, anxiety ${ }^{22} 103$ and fatigue $^{104}$ at follow-up (4-18 months).

\section{Recommendation 6: outcomes of PE}

The task force agreed that in order to provide evidence-based $\mathrm{PE}$, the various PE programmes need to be evaluated. To ensure valid evaluation the outcomes must reflect the programme objectives. The SLR revealed a great variation in evaluation criteria and use of outcome measures in the included studies. The specific educational objectives of the programmes were not always clear, making it difficult to judge whether the reported outcomes were matched to the educational objectives. For example, some studies reported the disease activity score with 28 joint counts (DAS-28), which are unlikely to be directly influenced by PE. ${ }^{25} 7475$

Many of the PE programmes can be characterised as complex interventions, which intend to influence various aspects of the 
disease impact on life. It is challenging to find the outcome measure(s) that best capture these aspects and the outcome measures need to be carefully reviewed before evaluation studies are conducted.

\section{Recommendation 7: competency in delivery of PE}

The task force agreed that PE should be delivered by competent HPs and patients. The majority of the studies included, comprised PE interventions delivered by HPs within a healthcare context. However, PE may also be delivered by trained patients and in community settings. ${ }^{92}$ Sixteen of the PE programmes were delivered by multidisciplinary HPs, ${ }^{25} \begin{array}{llllll}28 & 31 & 33 & 38 & 41 & 76-78\end{array}$ 88-9093959698 and 10 programmes were delivered by two different professionals, that is, OT and PT (3 studies), ${ }^{26} 3050$ nurse and rheumatologist (1 study), ${ }^{21}$ OT and rheumatologist (1 study), ${ }^{24}$ psychologist and nurse (1 study), ${ }^{39}$ psychologist and OT (1 study), ${ }^{36}$ pharmacist and nurse ( 1 study), ${ }^{91}$ and nutritionist and OT (1 study). ${ }^{79}$ Trained patients were involved in, or delivered two SMPs, ${ }^{75}$ two online programmes ${ }^{82} 83$ and one patient-led interactive workshop. ${ }^{89}$ The remaining interventions were provided by one HP. ${ }^{18-20} 23 \quad 27 \quad 2934 \quad 35 \quad 37 \quad 40 \quad 42 \quad 4967-71$ 7480868797 Which professionals should be involved, and how many, will depend on the aim, the topic and the context for the education. For example, physical exercise programmes provided by PTs may be combined with group educational sessions by other HPs, as appropriate ${ }^{5076}$ and some CBT programmes are provided by psychologists only. ${ }^{34} 37426768$ Other programmes are independent of profession, but require specific training in methods, such as CBT techniques ${ }^{36} 38$ and mindfulness. ${ }^{4041}$

\section{Recommendation 8: training competency for delivering PE}

The task force agreed that teaching competence is necessary alongside clinical expertise to deliver high quality PE. Only a few studies reported what skills and training providers of PE need. Qualitative studies exploring patients' perspectives on PE indicated requirements for knowledge and skills by educators. For example, patients wanted to receive clear explanation about test results, medication and self-management techniques. ${ }^{105} \mathrm{HPs}$ should have the ability to provide emotional support ${ }^{59} 64$ and to focus on acceptance of the patient's illness and its consequences. ${ }^{106}$ Moreover, patients experienced that the use of creative learning methods, such as guided discovery, metaphors, poetry, music and visual materials in groups facilitated their emotional and behavioural change processes ${ }^{57} 65$ and they wanted to have the possibility to exchange knowledge and experiences with other patients. ${ }^{56} \mathrm{HP}$, on the other hand, perceived that their delivery of knowledge and advice was influenced by their own attitudes and their abilities to interact with the patients. 107

\section{Research and educational agendas}

Box 1 presents the research agenda proposed by the task force, based on areas with only weak or limited evidence for PE. The two overarching principles (see table 1) should be applied when addressing each of these topics.

Box 2 presents the educational agenda, which encourages the development of training programmes to enhance and support HPs' opportunities to improve their educational competencies.

\section{DISCUSSION}

Eight recommendations for PE for people with IA were developed based on a SLR and expert opinions. The recommendations were formulated to be practical and feasible for providing evidence-based PE across all European countries. The strength

\section{Box 1 Research agenda for patient education (PE)}

- To evaluate, harmonise and/or further develop existing patient education outcomes, such as educational needs, goal attainment, etc, and if needed develop new outcomes, such as outcomes reflecting health literacy, health promotion, activity pacing, patients' needs, etc

- To develop guidelines on how to conduct and report studies in patient education

- To investigate which modes of delivery are best suited to meet which objectives of patient education, including the time point (in the disease trajectory) at which patient education is likely to produce maximum effects

- To study PE in other rheumatic conditions than rheumatoid arthritis

- To investigate educational needs in specific subgroups (ie men, patients with minority ethnic backgrounds and patients with lower literacy levels)

- To develop and evaluate PE for significant others (partners, spouses, family and carers)

- To conduct economic evaluations of PE interventions (using PE-sensitive outcomes and effects in relation to healthcare resource use).

- To investigate the long-term effects and cost-effectiveness of PE

- To gain insight into the working principles of PE-that is, the mechanism by which PE produces its effects; whether directly, or by modifying or mediating its effects through other outcomes

- To investigate how to best provide online/e-health PE programmes

- To investigate cross-cultural acceptability of PE programmes/ modes of delivery across Europe

- To define training requirements for PE provider

of evidence supporting the recommendations varies and a research agenda is proposed for areas with lack of evidence. A high level of expert agreement was achieved for all recommendations. An educational agenda was also formulated to support the development of competencies of HPs providing PE.

The included studies showed a trend towards greater inclusion of behavioural, cognitive and emotional aspects in the PE programmes during the last decade. This trend is reflected in the PE definition that the task force formulated as an overarching principle, stating that PE should enable people to manage their life with IA and optimise their health and well-being rather than be limited to the disease. Some previous PE definitions have stated that $\mathrm{PE}$ is designed to improve patients' health behaviours. However, the patient representatives in the task force felt that

Box 2 Educational agenda for providers of patient education (PE)

1. Increase health professionals' knowledge on the process and practicalities of delivering and evaluating effective PE

2. Regular updating of PE skills/training is necessary to ensure provision of state of the art effective PE

3. Develop training programmes for health professionals within the European League Against Rheumatism (EULAR) 
this was rather patronising and therefore it was not included in the consensus definition. The definition emphasises that $\mathrm{PE}$ is an interactive learning process, not a one-way delivery of knowledge. Substantial evidence has shown that interactive counselling, either in combination with group sessions or in one-by-one consultations with a competent HP, has beneficial effects in terms of adherence to treatment regimens, behavioural change, use of selfmanagement strategies and well-being. ${ }^{19} 374972108$ In order to ensure the application of shared decision-making, HPs need to develop their communication skills, and patient representatives should be involved in all phases of designing, implementing and evaluating the interventions.

Surprisingly, the SLR included only a limited number of studies on online PE programmes, but these showed promising results on health status and levels of physical activity. ${ }^{82}{ }^{84}$ In our rapidly growing digital world, one may foresee that face-to-facemeetings will be more frequently replaced by online programmes, the impact of which will need evaluation.

A limitation to the generalisability of the recommendations is that the majority of patients who participated in the included studies was female, diagnosed with RA and had relatively long disease duration. The task force recognises that at present there is limited evidence for patients with AS and PsA. It is therefore suggested that the recommendations should be regarded as "points to consider" for this population. Furthermore, little is known about special educational needs for men, patients with minority ethnic backgrounds and patients with lower literacy levels, which needs attention in future research. A great diversity in the type of educational programmes was observed, varying from interventions with a primary focus on increasing knowledge and improving performance, to more therapeutic oriented interventions aiming at behavioural change and improving mental health status. ${ }^{3} 5103$ Also, a wide range of outcome measures was used and most studies reported multiple outcomes, limiting comparison of the effectiveness of the programmes. To be able to evaluate the programmes more stringently and to compare relevant interventions, the task force recommends harmonisation of outcomes, tailored to the programme goals and content and to the patients needs. Furthermore, the task force has proposed that existing outcomes should be evaluated, and new outcome measures should be developed, if needed. The task force was not aware of any unpublished studies with negative results. Nevertheless, due to publication bias some positive effects of PE may potentially have been overestimated.

A methodological limitation of the SLR is that the task force decided to include all types of studies that could give insight in $\mathrm{PE}$, resulting in a great methodological variety. Consequently, it was not possible to use one formal quality scoring system. Four recommendations were of strength $\mathrm{A}$ and the remaining four were of strengths $C$ to $D$, that is, based on qualitative and crosssectional studies or expert opinions. However, the qualitative studies may provide valuable insight into the individual patient's needs and expectations, which should be regarded as the core of PE programmes.

The use of a multidisciplinary task force, including patients, is one of the strengths of this study. Ideally, the task force should also have included a dietician and a pharmacist as the educational activities comprise lifestyle changes and adherence to medication. However, we believe that these issues have been addressed by the comprehensive SLR. Another strength is the high level of agreement with the recommendations among the members of the task force and the consultation group. However, the level of agreement will have to be further evaluated in a wider population of patients and HPs with interest and expertise in this field during the dissemination and evaluation of the recommendations.
The task force agreed on a research agenda to gain further insight in the qualitative and quantitative aspects of $\mathrm{PE}$, including working mechanisms of PE, developing and harmonising PE outcomes, economic evaluations and cross-cultural acceptability of PE programmes across European countries. The educational agenda states that providers of PE need regular updates of their skills in order to deliver effective PE. The task force proposes that training of educational skills should be integrated in EULAR courses for HPs and rheumatologists.

Effective dissemination, implementation and evaluation of these recommendations across European countries demand a clear implementation strategy. Barriers and facilitators for implementation of $\mathrm{PE}$ as an integral part of standard care for all people with IA must be assessed within each country and appropriate support and education must be provided. This strategy will need further support from EULAR.

In conclusion, eight evidence-based and expert-opinion-based recommendations for PE for people with IA were developed. The dissemination and application of the recommendations should allow establishment of core standards for PE across Europe. Further evaluation will be necessary to ensure relevance and effective application.

\section{Author affiliations}

${ }^{1}$ Department of Rheumatology, National Advisory Unit on Rehabilitation in Rheumatology, Diakonhjemmet Hospital, Oslo, Norway

${ }^{2}$ School of Healthcare, University of Leeds, Leeds, UK and Leeds Institute of Rheumatic and Musculoskeletal Medicine, University of Leeds, Leeds, UK

${ }^{3}$ Centre for Innovation and Leadership in Health Faculty of Health Sciences University of Southampton Highfield, Southampton, UK

${ }^{4}$ Nyborg, Denmark

${ }^{5}$ Department of Psychology, University of Twente, Health \& Technology, Enschede, The Netherlands

${ }^{6}$ Division of physiotherapy, Department of Neurobiology, Care Sciences and Society, Karolinska Institutet, Stockholm, Sweden

${ }^{7}$ Department of Patient \& Care/ Department of Rheumatology, Maastricht University Medical Center, Maastricht, The Netherlands

${ }^{8}$ CAPHRI, School for Public Health and Primary Care, University of Maastricht, Maastricht, The Netherlands

${ }^{9}$ Sorbonne Universités, Institut Pierre Louis d'Epidémiologie et de Santé Publique,

Paris, France

${ }^{10}$ Department of rheumatology, AP-HP, Pitié Salpêtrière Hospital, Paris, France

${ }^{11}$ Institute of Rheumatology, Prague, Czech Republic

${ }^{12}$ Department of National Team, Portuguese Cycling Federation, Lisbon, Portugal

${ }^{13}$ Institute of Physiotherapy, School of Health Professions, Zurich University of Applied Sciences, Winterthur, Switzerland

${ }^{14}$ Institute for Regional Health Research, University of Southern Denmark, Odense, Denmark

${ }^{15}$ Hospital of Southern Jutland, Aabenraa, Denmark

${ }^{16}$ King Christian X's Hospital for Rheumatic Diseases, Graasten, Denmark

${ }^{17}$ Division of Rheumatology, Department of Medicine 3, Medical University of

Vienna, Vienna, Austria

${ }^{18}$ Department of Psychology, Health and Technology, University of Twente,

Enschede, The Netherlands

${ }^{19}$ Department of Medicine, Division of Rheumatology, Maastricht University Medical Center, Maastricht, The Netherlands

Acknowledgements The authors thank Kari Matre (medical librarian, Diakonhjemmet Hospital Library) for her contribution to the systematic literature review. The authors also thank the members of the consultation group for their involvement in the early conception of this project and for rating the recommendations. The consultation group consisted of Adewale Adebajo, Michael Backhouse, Ulrika Bergsten, Tricia Cornell, Jenny de la Torre-Aboki, Silvia Garcia Diaz, Ricardo Ferreira, Kjersti Gronning, Bernadette Hardware, Agnes Kocher, Marja Leena Kukkurainen, Ingrid Larsson, Azucena Pedraz Marcos, Andrea Marques, Jorit Meesters, Sue Oliver, David Pickles, Birgit Prodinger, Sarah Ryan and Karen Vinall.

Contributors HAZ was the research fellow for the project, undertaking the SLR; $\mathrm{MN}$ and AvT were the project convenors, AvT being the epidemiologist directing the SLR. All authors have contributed substantially by participating in the development of the recommendations, revising the manuscript critically for important intellectual content and approved the final version for publication. 
Funding This study was supported by the European League Against Rheumatism (EULAR), Grant reference: HPR024.

\section{Competing interests None.}

Provenance and peer review Not commissioned; externally peer reviewed.

\section{REFERENCES}

1 Combe $B$, Landewé $R$, Lukas $C$, et al. EULAR recommendations for the management of early arthritis: report of a task force of the European Standing Committee for International Clinical Studies Including Therapeutics (ESCISIT). Ann Rheum Dis 2007:66:34-45

2 Zochling J, van der Heijde D, Burgos-Vargas R, et al. ASAS/EULAR recommendations for the management of ankylosing spondylitis. Ann Rheum Dis 2006;65:442-52.

3 Albano MG, Giraudet-Le Quintrec JS, Crozet C, et al. Characteristics and development of therapeutic patient education in rheumatoid arthritis: analysis of the 2003-2008 literature. Joint Bone Spine 2010;77:405-10.

4 Riemsma RP, Taal E, Kirwan JR, et al. Systematic review of rheumatoid arthritis patient education. Arthritis Rheum 2004;51:1045-59.

5 Niedermann K, Fransen J, Knols R, et al. Gap between short- and long-term effects of patient education in rheumatoid arthritis patients: A systematic review. Arthritis Care Res 2004;51:388-98.

6 Astin JA, Beckner W, Soeken K, et al. Psychological interventions for rheumatoid arthritis: a meta-analysis of randomized controlled trials. Arthritis Rheum 2002:47:291-302.

7 Christie A, Jamtvedt G, Dahm KT, et al. Effectiveness of nonpharmacological and nonsurgical interventions for patients with rheumatoid arthritis: an overview of systematic reviews. Phys Ther 2007;87:1697-715.

8 Hoving C, Visser A, Mullen PD, et al. A history of patient education by health professionals in Europe and North America: from authority to shared decision making education. Patient Educ Couns 2010;78:275-81.

9 Chewning B, Bylund $C L$, Shah B, et al. Patient preferences for shared decisions: a systematic review. Patient Educ Couns 2012:86:9-18.

10 Newman S, Steed L, Mulligan K. Self-management interventions for chronic illness. Lancet 2004;364:1523-37.

11 de Ridder D, Geenen R, Kuijer R, et al. Psychological adjustment to chronic disease. Lancet 2008;372:246-55.

12 Klarenbeek NB, Kerstens PJ, Huizinga TW, et al. Recent advances in the management of rheumatoid arthritis. BMJ 2010;341:c6942

13 John H, Hale ED, Treharne GJ, et al. Patient education on cardiovascular aspects of rheumatoid disease: an unmet need. Rheumatology (Oxford) 2007;46(10): 1513-16.

14 Vliet Vlieland TP, Hazes JM. Efficacy of multidisciplinary team care programs in rheumatoid arthritis. Semin Arthritis Rheum 1997;27:110-22.

15 Stamm T, Hill J. Extended roles of non-physician health professionals and innovative models of care within Europe: results from a web-based survey. Musculoskeletal Care 2011;9:93-101.

16 Visser A, Deccache A, Bensing J. Patient education in Europe: united differences. Patient Educ Couns 2001;44:1-5.

17 Dougados M, Betteridge N, Burmester GR, et al. EULAR standardised operating procedures for the elaboration, evaluation, dissemination, and implementation of recommendations endorsed by the EULAR standing committees. Ann Rheum Dis 2004:63:1172-6.

18 Homer D, Nightingale P, Jobanputra P. Providing patients with information about disease-modifying anti-rheumatic drugs: Individually or in groups? A pilot randomized controlled trial comparing adherence and satisfaction. Musculoskeletal Care 2009;7:78-92.

19 El MiedanyY, El Gaafary M, et al. Arthritis education: the integration of patient-reported outcome measures and patient self-management. Clin Exp Rheumatol 2011;30:899-904

20 Ravindran $V$, Jadhav $R$. The effect of rheumatoid arthritis disease education on adherence to medications and followup in Kerala, India. J Rheumatol 2013:40:1460-1.

21 Mohammad A, Kilcoyne A, Bond U, et al. Methotrexate information booklet study 2008. Clin Exp Rheumatol 2009;27:649-50.

22 Knittle K, Maes S, de Gucht V. Psychological interventions for rheumatoid arthritis: examining the role of self-regulation with a systematic review and meta-analysis of randomized controlled trials. Arthritis Care Res (Hoboken) 2010;62:1460-72.

23 Rudd RE, Blanch DC, Gall V, et al. A randomized controlled trial of an intervention to reduce low literacy barriers in inflammatory arthritis management. Patient Educ Couns 2009:75:334-9.

24 Neto BEL, Jennings F, Ohashi CB, et al. Evaluation of the efficacy of an educational program for rheumatoid arthritis patients. Clin Exp Rheumatol 2009;27:28-34

25 Giraudet-Le Quintrec JS, Mayoux-Benhamou A, Ravaud P, et al. Effect of a collective educational program for patients with rheumatoid arthritis: a prospective 12-month randomized controlled trial. J Rheumatol 2007;34:1684-91.
26 O'Brien AV, Jones $P$, Mullis $R$, et al. Conservative hand therapy treatments in rheumatoid arthritis-a randomized controlled trial. Rheumatology (Oxford) 2006;45:577-83.

27 Nunez M, Nunez E, Yoldi C, et al. Health-related quality of life in rheumatoid arthritis: therapeutic education plus pharmacological treatment versus pharmacological treatment only. Rheumatol Int 2006;26:752-7.

28 Masiero S, Boniolo A, Wassermann L, et al. Effects of an educational-behavioral joint protection program on people with moderate to severe rheumatoid arthritis: a randomized controlled trial. Clin Rheumatol 2007;26: 2043-50.

29 Brodin N, Eurenius E, Jensen I, et al. Coaching patients with early rheumatoid arthritis to healthy physical activity: a multicenter, randomized, controlled study. Arthritis Rheum 2008;59:325-31.

30 Hammond A, Bryan J, Hardy A. Effects of a modular behavioural arthritis education programme: a pragmatic parallel-group randomized controlled trial. Rheumatology (Oxford) 2008;47:1712-18.

31 Mathieux R, Marotte H, Battistini L, et al. Early occupational therapy programme increases hand grip strength at 3 months: results from a randomised, blind, controlled study in early rheumatoid arthritis. Ann Rheum Dis 2009;68: 400-3.

$32 \mathrm{Oh} \mathrm{H}$, Seo W. Decreasing pain and depression in a health promotion program for people with rheumatoid arthritis. J Nurs Scholarsh 2003;35:127-32.

33 Abourazzak F, El Mansouri L, Huchet D, et al. Long-term effects of therapeutic education for patients with rheumatoid arthritis. Joint Bone Spine 2009;76:648-53.

34 Zautra AJ, Davis MC, Reich JW, et al. Comparison of cognitive behavioral and mindfulness meditation interventions on adaptation to rheumatoid arthritis for patients with and without history of recurrent depression. J Consult Clin Psychol 2008;76:408-21.

35 Barsky AJ, Ahern DK, Orav EJ, et al. A randomized trial of three psychosocial treatments for the symptoms of rheumatoid arthritis. Semin Arthritis Rheum 2010:40:222-32.

36 Hewlett S, Ambler N, Almeida C, et al. Self-management of fatigue in rheumatoid arthritis: a randomised controlled trial of group cognitive-behavioural therapy. Ann Rheum Dis 2011;70:1060-7.

37 Sharpe L, Schrieber L. A blind randomized controlled trial of cognitive versus behavioral versus cognitive-behavioral therapy for patients with rheumatoid arthritis. Psychother Psychosom 2012;81:145-52.

38 van Lankveld W, van Helmond T, Naring G, et al. Partner participation in cognitive-behavioral self-management group treatment for patients with rheumatoid arthritis. J Rheumatol 2004;31:1738-45.

39 Carson JW, Keefe FJ, Affleck G, et al. A comparison of conventional pain coping skills training and pain coping skills training with a maintenance training component: a daily diary analysis of short- and long-term treatment effects. J Pain 2006;7:615-25

40 Pradhan EK, Baumgarten M, Langenberg P, et al. Effect of Mindfulness-Based Stress Reduction in rheumatoid arthritis patients. Arthritis Rheum 2007:57:1134-42.

41 Zangi HA, Mowinckel $P$, Finset $A$, et al. A mindfulness-based group intervention to reduce psychological distress and fatigue in patients with inflammatory rheumatic joint diseases: a randomised controlled trial. Ann Rheum Dis 2012;71: 911-17.

42 Sharpe L, Sensky T, Timberlake N, et al. Long-term efficacy of a cognitive behavioural treatment from a randomized controlled trial for patients recently diagnosed with rheumatoid arthritis. Rheumatology (Oxford) 2003;42: 435-41.

43 Leung YY, Tam LS, Lee KW, et al. Involvement, satisfaction and unmet health care needs in patients with psoriatic arthritis. Rheumatology (Oxford) 2009;48: 53-6.

44 Kristiansen TM, Primdahl J, Antoft R, et al. Everyday life with rheumatoid arthritis and implications for patient education and clinical practice: a Focus Group Study. Musculoskeletal care 2012;10:29-38.

45 Ørnbjerg LM, Andersen HB, Kryger $\mathrm{P}$, et al. What do patients in rheumatologic care know about the risks of NSAIDs? J Clin Rheumatol 2008;14: 69-73.

46 Bode C, Taal E, Emons PAA, et al. Limited results of group self-management education for rheumatoid arthritis patients and their partners: explanations from the patient perspective. Clin Rheumatol 2008;27:1523-8.

47 Meesters JJL, Vlieland TPMV, Hill J, et al. Measuring educational needs among patients with rheumatoid arthritis using the Dutch version of the Educational Needs Assessment Tool (DENAT). Clin Rheumatol 2009;28:1073-7.

48 Mitton DL, Treharne GJ, Hale ED, et al. The health and life experiences of mothers with rheumatoid arthritis: a phenomenological study. Musculoskeletal Care 2007:5:191-205.

49 Gronning K, Skomsvoll JF, Rannestad T, et al. The effect of an educational programme consisting of group and individual arthritis education for patients with polyarthritis-a randomised controlled trial. Patient Educ Couns 2012;88: 113-20. 
50 Mayoux-Benhamou A, Giraudet-Le Quintrec JS, Ravaud P, et al. Influence of patient education on exercise compliance in rheumatoid arthritis: a prospective 12-month randomized controlled trial. J Rheumatol 2008;35:216-23.

51 Sjoquist ES, Brodin N, Lampa J, et al. Physical activity coaching of patients with rheumatoid arthritis in everyday practice: a long-term follow-up. Musculoskeletal Care 2011;9:75-85.

52 Schildmann J, Grunke M, Kalden JR, et al. Information and participation in decision-making about treatment: a qualitative study of the perceptions and preferences of patients with rheumatoid arthritis. J Med Ethics 2008;34:775-9.

53 Hirsh $D$, Clerehan $R$, Staples $M$, et al. Patient assessment of medication information leaflets and validation of the Evaluative Linguistic Framework (ELF). Patient Educ Couns 2009;77:248-54.

54 Brand C, Claydon-Platt K, McColl G, et al. Meeting the needs of people diagnosed with rheumatoid arthritis: an analysis of patient-reported experience. J Nurs Healthc Chronic IIIn 2010;2:75-83.

55 Bergsten U, Bergman S, Fridlund B, et al. "Striving for a good life" — the management of rheumatoid arthritis as experienced by patients. Open Nurs J 2011;5:95-101.

56 Primdahl J, Wagner L, Hørslev-Petersen K. Being an outpatient with rheumatoid arthritis-a focus group study on patients' self-efficacy and experiences from participation in a short course and one of three different outpatient settings. Scand I Caring Sci 2011;25:394-403.

57 Dures E, Kitchen K, Almeida C, et al. "They didn't tell us, they made us work it out ourselves": Patient perspectives of a cognitive-behavioral program for rheumatoid arthritis fatigue. Arthritis Care Res 2012;64:494-501.

58 Zwikker $\mathrm{H}$, van den Bemt B, van den Ende $\mathrm{C}$, et al. Development and content of a group-based intervention to improve medication adherence in non-adherent patients with rheumatoid arthritis. Patient Educ Couns 2012;89:143-51.

59 Ryan S, Lillie K, Thwaites C, et al. 'What I want clinicians to know' - experiences of people with arthritis. Br J Nurs 2013;22:808-12.

60 Werner AM, Kaliski S, Salazar K, et al. Knowledge about their disease and treatment among patients with rheumatoid arthritis. [Spanish\}. Rev Med Chil 2006;134:1500-6.

61 Adab P, Rankin E, Witney A, et al. Use of a corporate needs assessment to define the information requirements of an arthritis resource centre in Birmingham: comparison of patients' and professionals' views. Rheumatology (Oxford) 2004:43:1513-18.

62 Claudepierre P, Flipo RM, Sibilia J, et al. Patient knowledge of their disease: a French multicenter study in ankylosing spondylitis. Joint Bone Spine 2004;71:550-6.

63 Ahlmen M, Nordenskiold U, Archenholtz B, et al. Rheumatology outcomes: the patient's perspective. A multicentre focus group interview study of Swedish rheumatoid arthritis patients. Rheumatology (Oxford) 2005;44:105-10

64 Radford S, Carr M, Hehir M, et al. 'It's quite hard to grasp the enormity of it': Perceived needs of people upon diagnosis of rheumatoid arthritis. Musculoskelet Care 2008;6:155-67.

65 Zangi HA, Hauge MI, Steen E, et al. "I am not only a disease, I am so much more." Patients with rheumatic diseases' experiences of an emotion-focused group intervention. Patient Educ Couns 2011;85:419-24.

66 Cumming J, Hull RG. The information and support needs of people living with rheumatoid arthritis [abstract]. Rheumatology (Oxford) 2012;51(Suppl 3):iii159.

67 Sharpe L, Allard S, Sensky T. Five-year followup of a cognitive-behavioral intervention for patients with recently-diagnosed rheumatoid arthritis: effects on health care utilization. Arthritis Rheum 2008;59:311-16.

68 Parker JC, Smarr KL, Slaughter JR, et al. Management of depression in rheumatoid arthritis: a combined pharmacologic and cognitive-behavioral approach. Arthritis Rheum 2003;49:766-77.

69 de Brouwer SJ, Kraaimaat FW, Sweep FC, et al. Psychophysiological responses to stress after stress management training in patients with rheumatoid arthritis. PLoS ONE 2011;6:e27432.

70 Hammond A, Freeman K. The long-term outcomes from a randomized controlled trial of an educational-behavioural joint protection programme for people with rheumatoid arthritis. Clin Rehabil 2004;18:520-8.

71 Hammond A, Young A, Kidao R. A randomised controlled trial of occupational therapy for people with early rheumatoid arthritis. Ann Rheum Dis 2004:63:23-30.

72 Niedermann K, Buchi S, Ciurea A, et al. Six and 12 months' effects of individual joint protection education in people with rheumatoid arthritis: a randomized controlled trial. Scand I Occup Ther 2012;19:360-9.

73 Walker D, Adebajo A, Heslop P, et al. Patient education in rheumatoid arthritis: the effectiveness of the ARC booklet and the mind map. Rheumatology (Oxford) 2007:46:1593-6.

74 Bearne LM, Manning VL, Scott DL, et al. A brief exercise and self management programme improves upper limb disability in people with early rheumatoid arthritis. [abstract]. Arthritis Rheum 2012;64(Suppl10):2439.

75 Conn DL, Pan Y, Easley KA, et al. The effect of the Arthritis Self-Management Program on outcome in African Americans with rheumatoid arthritis served by a public hospital. Clin Rheumatol 2013;32:49-59.
76 Breedland I, van Scheppingen C, Leijsma M, et al. Effects of a group-based exercise and educational program on physical performance and disease self-management in rheumatoid arthritis: a randomized controlled study. Phys Ther 2011:91:879-93.

77 Masiero S, Bonaldo L, Pigatto M, et al. Rehabilitation treatment in patients with ankylosing spondylitis stabilized with tumor necrosis factor inhibitor therapy: a randomized controlled trial. J Rheumatol 2011;38:1335-42.

78 Krauth C, Rieger J, Bonisch A, et al. [Costs and benefits of an education program for patients with ankylosing spondylitis as part of an inpatient rehabilitation programs-study design and first results]. Z Rheumatol 2003;62(Suppl 2): II14-16.

79 McKellar G, Morrison E, McEntegart A, et al. A pilot study of a Mediterranean-type diet intervention in female patients with rheumatoid arthritis living in areas of social deprivation in Glasgow. Ann Rheum Dis 2007;66:1239-43.

80 Van den Berg M, Ronday $\mathrm{H}$, Peeters $\mathrm{A}$, et al. Using internet technology to deliver a home-based physical activity intervention for patients with rheumatoid arthritis: a randomized controlled trial. Arthritis Care Res 2006;55:935-45.

81 van den Berg MH, Ronday HK, Peeters AJ, et al. Engagement and satisfaction with an Internet-based physical activity intervention in patients with rheumatoid arthritis. Rheumatology (Oxford) 2007;46:545-52.

82 Lorig KR, Ritter PL, Laurent $\mathrm{DD}$, et al. The internet-based arthritis self-management program: a one-year randomized trial for patients with arthritis or fibromyalgia. Arthritis Rheum 2008;59:1009-17.

83 Meesters JJ, de Boer IG, van den Berg MH, et al. Evaluation of a website providing information on regional health care services for patients with rheumatoid arthritis: an observational study. Clin Rheumatol 2012;31:637-45.

84 Hurkmans EJ, van den Berg MH, Ronday KH, et al. Maintenance of physical activity after Internet-based physical activity interventions in patients with rheumatoid arthritis. Rheumatology (Oxford) 2010;49:167-72.

85 Savelkoul M, de Witte L, Post M. Stimulating active coping in patients with rheumatic diseases: a systematic review of controlled group intervention studies. Patient Educ Couns 2003;50:133-43.

86 Niedermann K, de Bie RA, Kubli R, et al. Effectiveness of individual resource-oriented joint protection education in people with rheumatoid arthritis. A randomized controlled trial. Patient Educ Couns 2011;82:42-8.

87 Johansson K, Katajisto J, Salantera S. Pre-admission education in surgical rheumatology nursing: towards greater patient empowerment. J Clin Nurs 2010;19:2980-8.

88 Kennedy CA, Beaton DE, Warmington $\mathrm{K}$, et al. Prescription for education: development, evaluation, and implementation of a successful interprofessional education program for adults with inflammatory arthritis. J Rheumatol 2011;38:2247-57.

89 Brosseau L, Lineker S, Bell M, et al. People getting a grip on arthritis: a knowledge transfer strategy to empower patients with rheumatoid arthritis and osteoarthritis. Health Educ J 2010;71:255-67.

90 Sudre A, Figuereido IT, Lukas C, et al. On the impact of a dedicated educational program for ankylosing spondylitis: effect on patient satisfaction, disease knowledge and spinal mobility, a pilot study. Joint Bone Spine 2012;79: 99-100.

91 Stockl KM, Shin JS, Lew HC, et al. Outcomes of a rheumatoid arthritis disease therapy management program focusing on medication adherence. I Manag Care Pharm 2010;16:593-604.

92 Chui D, Lau J, Yau I. An outcome evaluation study of the rheumatoid arthritis self-management programme in Hong Kong. Psychol Health Med 2004;9:286-92.

93 Siu AM, Chui DY. Evaluation of a community rehabilitation service for people with rheumatoid arthritis. Patient Educ Couns 2004;55:62-9.

94 Lacaille D, White MA, Rogers PA, et al. A proof-of-concept study of the "employment and arthritis: Making it work" program. Arthritis Care Res 2008;59:1647-55.

95 O'Gorman A, Nolan M, Doyle C, et al. R.A.I.S.A. (Rheumatoid Arthritis Information, Support and Education): a four week multidisciplinary education programme [abstract]. Phys Ther Rev 2008;13:119-20.

96 Vriezekolk JE, Eijsbouts AM, van Lankveld WG, et al. An acceptance-oriented cognitive-behavioral therapy in multimodal rehabilitation: a pre-post test evaluation in highly distressed patients with rheumatic diseases. Patient Educ Couns 2013;91:357-63.

97 Bagheri-Nesami M, Mohseni-Bandpei MA, Shayesteh-Azar M. The effect of Benson Relaxation Technique on rheumatoid arthritis patients: extended report. Int J Nurs Pract 2006;12:214-19.

98 Zangi HA, Finset A, Steen E, et al. The effects of a vitality training programme on psychological distress in patients with inflammatory rheumatic diseases and fibromyalgia: a 1-year follow-up. Scand I Rheumatol 2009;38:231-2.

99 Bandura A. Self-efficacy: The exercise of control. New York: Freeman, 1997.

100 Sharpe L, Curran L. Understanding the process of adjustment to illness. Soc Sci Med 2006;62:1153-66.

101 Lorig KR, Holman H. Self-management education: history, definition, outcomes, and mechanisms. Ann Behav Med 2003;26:1-7. 


\section{Recommendation}

102 Hofmann SG, Asmundson GJ. Acceptance and mindfulness-based therapy: new wave or old hat? Clin Psychol Rev 2008;28:1-16.

103 Dissanayake RK, Bertouch JV. Psychosocial interventions as adjunct therapy for patients with rheumatoid arthritis: a systematic review. Int I Rheum Dis 2010;13:324-34

104 Cramp F, Hewlett S, Almeida C, et al. Non-pharmacological interventions for fatigue in rheumatoid arthritis. Cochrane Database Syst Rev 2013;8:CD008322.

105 Ward V, Hill J, Hale C, et al. Patient priorities of care in rheumatology outpatient clinics: a qualitative study. Musculoskeletal Care 2007;5:216-28.

106 Hamnes B, Hauge MI, Kjeken I, et al. 'I have come here to learn how to cope with my illness, not to be cured': A Qualitative Study of Patient Expectations Prior to a One-Week Self-Management Programme. Musculoskeletal Care 2011;9:200-10.

107 Bergsten U, Bergman S, Fridlund B, et al. "Delivering knowledge and advice": Healthcare providers' experiences of their interaction with patients' management of rheumatoid arthritis. Int I Qual Stud Health Well-bein 2011:6:8473-81.

108 Sjoquist ES, Almqvist L, Asenlof P, et al. Physical-activity coaching and health status in rheumatoid arthritis: a person-oriented approach. Disabil Rehabil 2010;32:816-25. 